\title{
A Comparison of Ground Beetle Assemblages (Coleoptera: Carabidae) between Birch Forests of Continuous and Isolated Peat Bog Habitats in Belarusian Lake District ${ }^{+}$
}

\author{
Gennadi Sushko
}

Citation: Sushko, G. A Comparison of Ground Beetle Assemblages (Coleoptera: Carabidae) between Birch Forests of Continuous and Isolated Peat Bog Habitats in Belarusian Lake District, in Proceedings of the 1st International Electronic Conference on

Entomology, 1-15 July 2021, MDPI: Basel, Switzerland,

doi:10.3390/IECE-10564

Published: 2 July 2021

Publisher's Note: MDPI stays neutral with regard to jurisdictional claims in published maps and institutional affiliations.

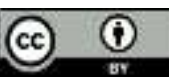

Copyright: ( 2021by the authors Submitted for possible open access publication under the terms and conditions of the Creative Commons Attribution (CC BY) license (http://creativecommons.org/licenses /by/4.0/).
Vitebsk State University, Department of Ecology and Geography, 210015, Vitebsk, Belarus; gennadisu@tut.by Correspondence: gennadisu@tut.by; Tel.: +37533 3804442

+ Presented at the 1st International Electronic Conference on Entomology (IECE 2021), 1-15 July 2021; Available online: https://iece.sciforum.net/.

\begin{abstract}
Largest in Central Europe ancient and almost intact Belarusian peat bogs are habitats with very specific environmental conditions and biodiversity. They themselves are island-like ecosystems, but in addition they are containing small raised islands of mineral soil within peat, covered by forest. In this study, the ground beetle diversity, species composition and abundance according to their habitat affinity, mean body size and wing form between isolated birch forests on the mineral and peat soils within the peat bog and adjacent continuous birch forests were compared. The diversity respond to isolation most clearly in birch forests with sphagnum cover, while in forests on the mineral soils the diversity parameters were similar to continuous adjacent forests. Distinct separation of carabid assemblages of continuous and isolated habitats was detected only in terms of species composition. There is a clear increase of the abundances of forest species from continuous to isolated forests on mineral soil, whereas in the forests on peat soil specialized peat bog species were dominated. In isolated forests, a gradually decrease of the abundances of large-sized and brachypterous species and increase of medium-sized beetles were recorded. However, the abundance of macropterous species was the most abundant only in isolated forest on mineral soil. Thus, the ground beetle assemblages of the two birch forest types within peat bog respond in a different way to the isolation and recorded differences can be probably explained also a variety of environmental factors.
\end{abstract}

Keywords: ground beetles; diversity; peat bogs; species traits; isolation; continuity

\section{Introduction}

Largest in Central Europe ancient and almost intact Belarusian peat bogs are habitats with very specific environmental conditions and biodiversity. Many peat bog dwellers have habitat requirements, such as nutrient poor and acidic conditions, specific subarctic or boreal host plants. As a result, European peat bogs formed habitat islands which rise up to several meters by accumulation of sphagnum peat above the level of the surrounding landscapes [1]. In Belarus they are extend over thousands of hectares and rise up to 5-7 meters. In such extreme acidic, wet and cold habitats, formation of the forests or meadows is prevented [2]. Peat bogs themselves are island-like ecosystems, but in addition they are containing small raised islands of mineral soil within peat covered by forests. The theory of island biogeography predicts the effects of habitat isolation on community composition, species richness and persistence. It is known that in isolated habitats species richness generally increases with habitat size and heterogeneity [3]. Probably, peat bog ground beetles can follow this pattern. In addition, the carabid morphology and species traits can also be changed. 
Body size is an essential proxy for the adaptation, various physiology and lifehistory parameters [4], and is also linked to spatial distribution [5]. Changes in body size distribution within assemblages are one of the most fundamental responses to island environments [6]. Carabid beetles are different according to their wing morphology. Brachypterous or short-winged species have lower dispersal ability, while macropterous or winged species are better at dispersal [7]. As a result, wing morphology plays an important role for ground beetle spatial distribution.

In this study, I expected the following: 1) there are significant differences in species richness, abundance, and diversity of ground beetle assemblages between isolated peat bog birch forests and adjacent continuous birch forests; 2) a lower abundance of forest specialists in the isolated peat bog birch forests, in which more generalist and specialized peat bog species from the surrounding peatlands could be expected than in adjacent continuous birch forests; 3 ) carabid body size and wing morphology vary significantly in the isolated peat bog birch forests and adjacent continuous birch forests.

\section{Materials and Methods}

\subsection{Study area and data collection}

Three habitats types such as isolated birch forests on the mineral and peat soils within the peat bog and continuous birch forests outside peat bogs were selected. The forest type was determined in accordance with prevailing understory vegetation. Isolated birch forests (Betuletum myrtillosum) on the mineral soil islands within the peat bog (BFI) covered by Betula pubescens. The understory vegetation contains predominantly Vaccinium myrtillus. Also here Vaccinium vitis-idaea, Festuca ovina, Calamagrostis epigeios, Pterídium aquilínum were occurred. The area of such mineral soil islands was less than 1 hectare.

Isolated birch forests (Betuletum ledo-sphagnosum) on the peat soil (BFP) are located at the bog margin. Besides containing Betula pubescens, such forests supported a more heterogeneous plant community characterized by sphagnum mosses, ericaceous dwarf shrubs such as Ledum palustre, Chamaedaphne calyculata, Calluna vulgaris, Vaccinium oxycoccus, and as well as Eriophorum vaginatum occurs. The area of such birch forests was about 1 hectare.

The adjacent continuous birch forests (Betuletum myrtillosum) on the mineral soil outside peat bogs (BF) were covered predominantly by Vaccinium myrtillus. Also here Vaccinium vitis-idaea, Festuca ovina, Melampyrum pratense, Convallaria majalis and Pterídium aquilinum were occurred. This forest type are homogenous stands large ( $>2 \mathrm{ha}$ ) and were at least $500 \mathrm{~m}$ apart and at least $100 \mathrm{~m}$ from peat bog.

The height of the trees was recorded within $10 \mathrm{~m} \times 10 \mathrm{~m}$ plots of each study site of birch forests using the optical rangefinder RGK D 1500 and ranged from 8 to $12 \mathrm{~m}$ in all habitat types.

The study was conducted in 2020. Carabids were sampled using pitfall traps in the form of plastic cups $\left(250 \mathrm{~cm}^{3}\right)$ with a preservative liquid ( $100 \mathrm{ml}$ of $11 \%$ vinegar solution and $10 \mathrm{~g}$ of $\mathrm{NaCl}$ ). Each treatment was repeated 5 times in each of the 3 forest type. In total 15 research sites were selected. On each site 5 traps were placed $5 \mathrm{~m}$ apart. The traps were checked at 10-14 day intervals. Pitfall trapping was started in the first half of April and all traps were removed at the beginning of November. Ground beetle species were identified according to Freude et al. (2004) [8].

\subsection{Data analysis}

Habitat association of carabid species was determined on the basis of main habitat preference: habitat generalists, peat bog, forest and open habitats. Ground beetles were 
classified according to mean body sizes into following categories: small $(0-5 \mathrm{~mm})$, medium $(6-10 \mathrm{~mm})$, large $(11-15 \mathrm{~mm})$ and largest $(>15 \mathrm{~mm})$. The degree of hind wing development was defined as: brachypterous (short or no wings), macropterous (long wings), and dimorphic (both forms present). Data about habitat preferences, body size and wing morphology were gathered from Freude et al. (2004) [8], Aleksandrowicz (2014) [9] and personal measurements.

To estimate the potential number of species, the estimators Chao 2 and Jackknife 2 were used [10]. To examine the carabid diversity, Shannon $\left(\mathrm{H}^{\prime}\right)$ and Pielou's evenness $\left(\mathrm{J}^{\prime}\right)$ indexes were calculated. Prior to the analyses, the data were tested for normality using Shapiro-Wilk normality test. Differences of species richness, abundances, diversity indexes, habitat preferences and morphological characteristics were examined using Kruskal-Wallis test with Dunn's post hoc test (the level of significance $\mathrm{P}<0.05$, tests with Bonferroni correction). Non-metric multidimensional scaling (NMDS) based on the Bray-Curtis similarity index and analysis of similarity test (ANOSIM) were applied to assess of assemblage composition at the different forest types. Analyses were performed in R software and Past [10, 11].

\section{Results}

A total of 2,354 individuals belonging to 39 carabid species were collected. The mean species richness differed significantly (Kruskal-Wallis test, $\chi^{2}=11.15, p=0.003$ ) among the carabid assemblages of the three birch forest types. The lowest mean number of species in BFP $(7.0 \pm 0.54)$ was recorded, whereas in the BF $(14.87 \pm 0.96)$ and in BFI $(17.61 \pm 0.87)$ the numbers of species were similar (Dunn's post hoc test $\mathrm{P}>0.05$ ) (Figure 1a).

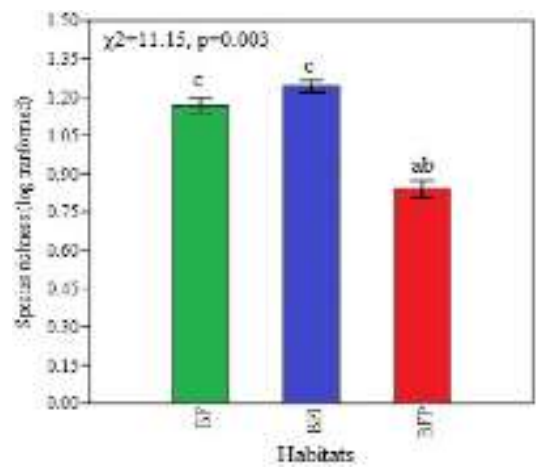

(a)

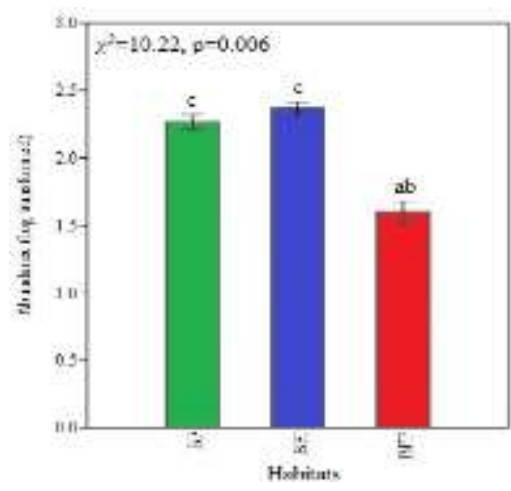

(b)

Figure 1. (a) Species richness and (b) abundance in carabid beetle assemblages of studied birch forest types: BF continuous birch forests, BFI - isolated birch forests on the mineral soil, BFP - isolated birch forests on the peat soil. Differences among habitats were tested using the Kruskal-Wallis test. The letters $(a, b, c)$ indicate significant differences (post-hoc Dunn's test; $\mathrm{P}<0.05$ ).

The non-parametric species richness estimators Chao 2 and Jackknife 2 showed expected species richness that is close to the actual number of observed species. The estimator Chao 2 showed that the mean number of carabid species in the studied birch forest types was 9.80-33.14 species suggesting that the observed total of 9-28 species represented $84.49 \%$ to $99.59 \%$ of the recorded species richness. The estimator Jackknife 2 showed that the mean species richness was $11.80-39.30$ species suggesting that the observed number species represented $71.79 \%$ to $99.59 \%$ of the recorded species richness.

The mean abundance differed significantly (Kruskal-Wallis test, $\chi^{2}=10.22, \mathrm{P}=0.006$ ) among the carabid assemblages of the three birch forest types. The lowest mean number of individuals in BFP $(42.2 \pm 6.40)$ was recorded, however the mean abundance in the BF (190.0 \pm 23.26$)$ and in BFI (238.6 \pm 25.37$)$ not differed significantly (Dunn's post hoc test $\mathrm{p}>$ 0.05) (Figure 1b). The six most abundant species in BF were Carabus granulatus $(25.63 \%)$, Pterostichus niger (24.68 \%), Poecilus versicolor (18.03\%), Carabus cancellatus (12.13\%), C. 
hortensis (5.27 \%), Amara communis (5.16 \%). The four most abundant species in BFI were Amara communis (44.96 \%), Calathus micropterus (15.60\%), Amara brunnea (12.33\%), Pterostichus niger (10.06 \%). Among abundant species in BFP were Agonum ericeti (34.59 $\%)$, Pterostichus diligens (20.37 \%), P. rhaeticus (19.90\%), Poecilus cupreus (11.37\%) and Pterostichus niger (7.58 \%).Of these, the only Pterostichus niger was generally abundant across all three birch forests types (Table A1). The mean values of Shannon index differed significantly (Kruskal-Wallis test, $\chi^{2}=6.72, \quad \mathrm{P}=0.03$ ) among the carabid assemblages of the three birch forest types. The lowest index value was recorded from the BFP $\left(\mathrm{H}^{\prime}=1.618 \pm 0.08\right)$. The mean Shannon index ranges in the BF $(1.916 \pm 0.04)$ and in BFI $(1.781 \pm 0.03)$ not differed significantly (Dunn's post hoc test $>0.05)$ (Figure 2a). In contrast, the Pielou evenness index was highest in the BFP $(\mathrm{J}=0.731)$ and low in BFI $(\mathrm{J}=$ $0.340)$ and $B F(J=0.468)$ (Figure $2 b)$.

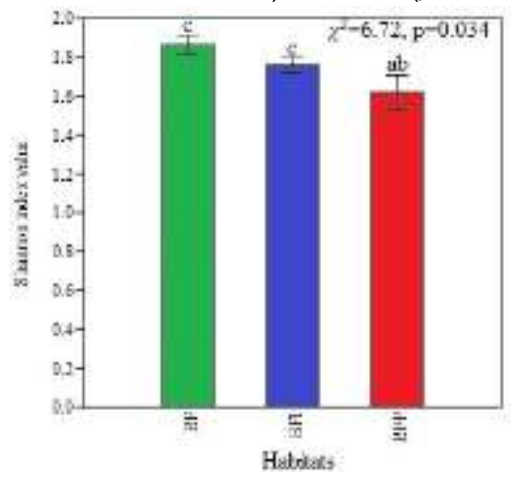

(a)

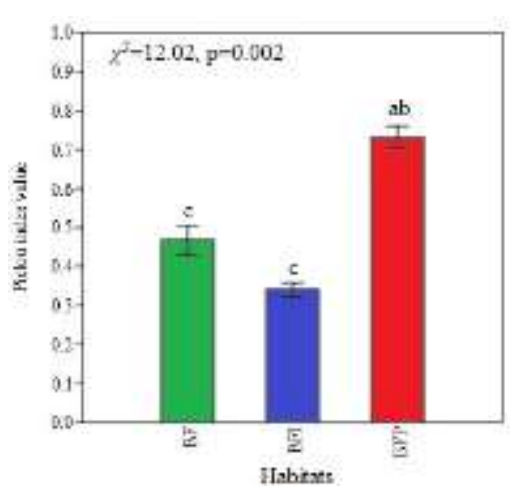

(b)

Figure 2. (a) Shannon index and (b) Pielou index values in carabid beetle assemblages of studied birch forest types: BF continuous birch forests, BFI - isolated birch forests on the mineral soil, BFP - isolated birch forests on the peat soil. Differences among habitats were tested using the Kruskal-Wallis test. The letters $(a, b, c)$ indicate significant differences (post-hoc Dunn's test; $\mathrm{P}<0.05)$.

NMDS ordination (stress: 0.11) showed a clear separation of ground beetle species composition. The assemblages sampled in the BFP were all more similar to BFI. On the other hand, BFP and BF were the most different (Figure 3). The ANOSIM was performed to test the significance of forest type in forming the ground beetle species composition. A significant difference in carabid species composition was detected (ANOSIM, R=0.893, $\mathrm{P}<0.001$ ). According to habitat preferences, $\mathrm{BF}$ and BFI were dominated by individuals of forest species (Kruskal-Wallis test, $\chi^{2}=4.62, \mathrm{P}=0.02$, Dunn's post Hoc test, $\mathrm{P}<0.05$ ). Nevertheless, abundances of open habitat species (in BF) and generalists (in BFI) were high as well. The abundance of individuals belonging to the forest specialists significantly increased in BFI, and the opposite was observed for open habitat dwellers. Least of all forest dwellers in BFP were found (Figure 4). These habitats were dominated significantly by peat bog specialists (Dunn's post Hoc test, $\mathrm{P}<0.05$ ).

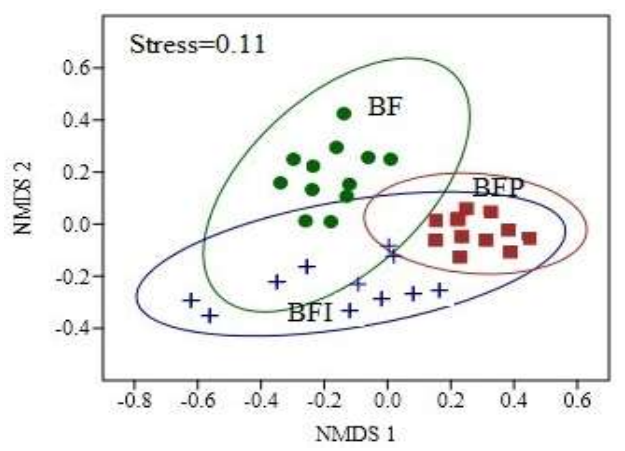

Figure 3. NMDS-ordination diagram of the carabid beetle assemblages of studied birch forest types: BF - continuous birch forests, BFI - isolated birch forests on the mineral soil, BFP - isolated birch forests on the peat soil. 

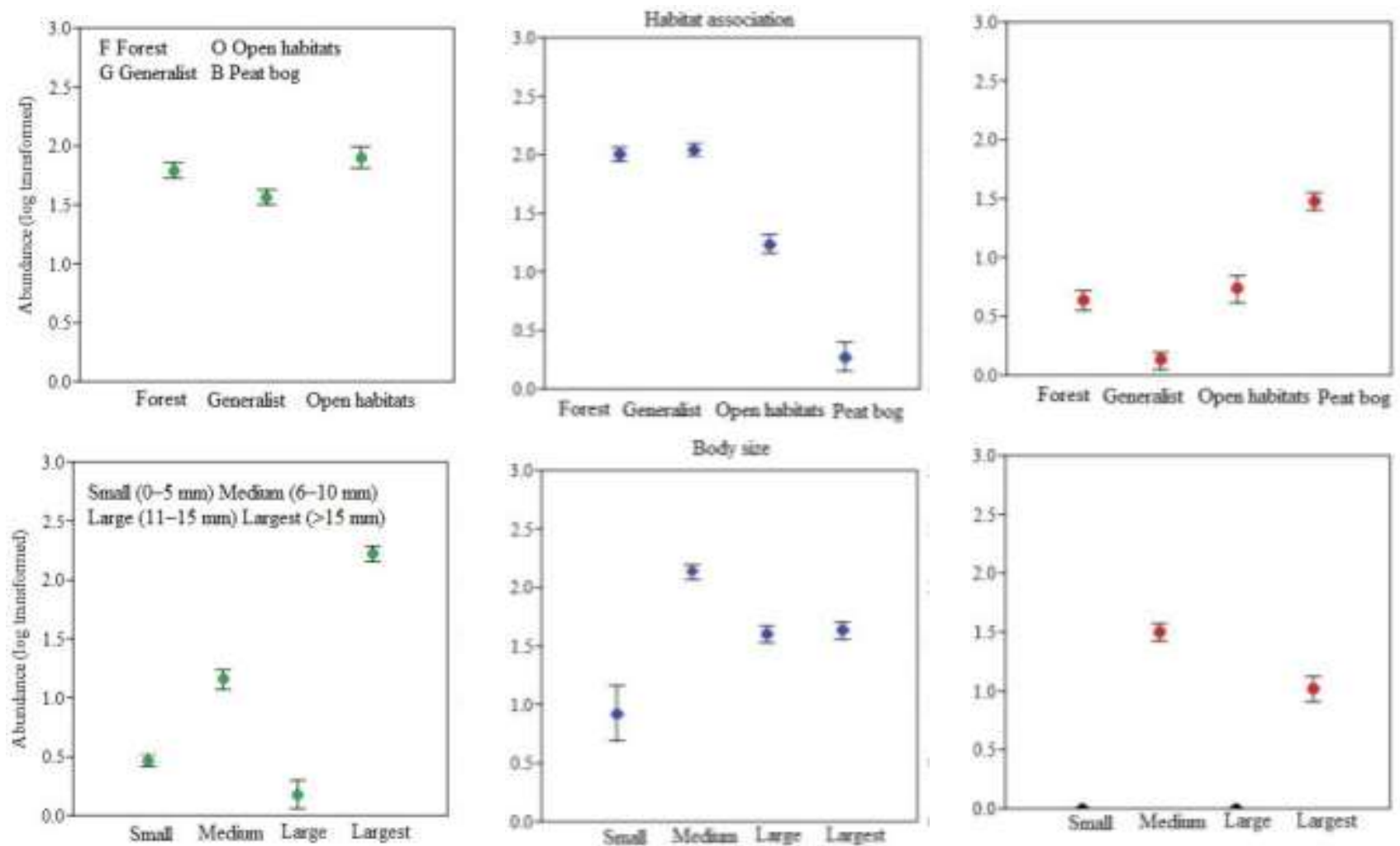

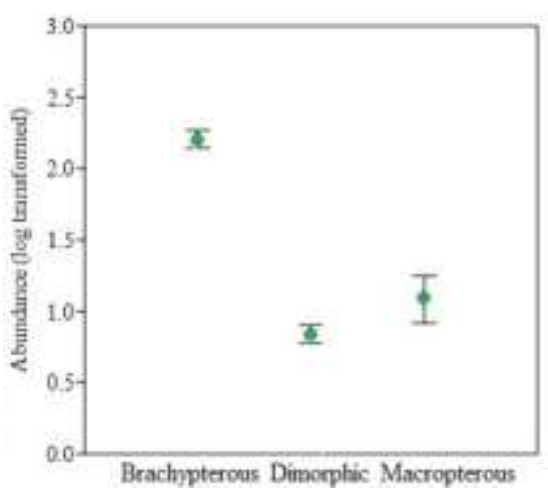

(a)

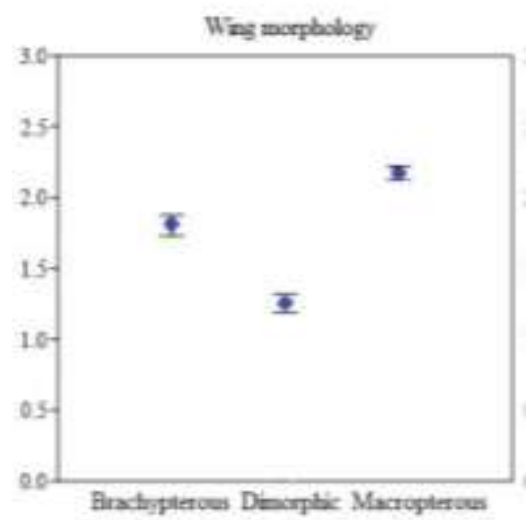

(b)

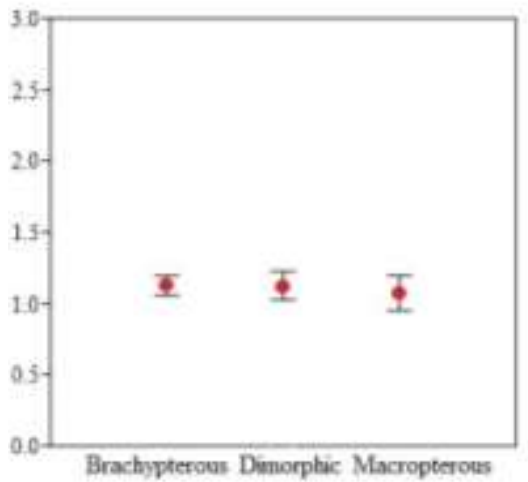

(c)

Figure 4. Plots of the distribution of traits of carabid species of studied birch forest types: (a) continuous birch forests, (b) isolated birch forests on the mineral soil, (c) isolated birch forests on the peat soil.

In terms of morphological characteristics, carabid assemblages of all studied birch forests were dissimilarly. The BF dominated significantly (Kruskal-Wallis test, $\chi^{2}=6.72$, $\mathrm{p}=0.03$ ) by individuals of largest body size category, while the BFI and BFP were dominated by medium-sized individuals. According to the degree of hind wing development in the BF the most of the individuals were brachypterous. The BFI was equally dominated by macropterous and brachypterous individuals (Figure 4). In the BFP abundance of dimorphic, macropterous and brachypterous individuals not differed significantly (Dunn's post hoc test $\mathrm{p}>0.05$ ).

\section{Discussion}

Carabid abundance, species richness and diversity significantly decreased only in Betuletum ledo-sphagnosum forest type compared to continuous forest, while in another isolated forest type such as Betuletum myrtillosum and in continuous forests these 
parameters were similar. At the same time, it is known about a higher carabid diversity in small isolated forest fragments [13]. In this study, diversity of carabid assemblages of habitats covered by sphagnum mosses responded more strongly to isolation than in assemblages of habitats covered only by shrubs. This pattern may be caused by more extremely microclimatic and soil conditions of peat bog sphagnum cover such as strong acidity, moisture and temperature variation. Apparently higher habitat stability in the forested sites without sphagnum cover on the mineral soil within peatland can affect the more favorable conditions for ground beetles. As a result, in these habitats and in continuous birch forests diversity parameters were similar.

On the other hand, the species composition of the ground beetles, both continuous and isolated habitats, differed significantly. In terms of dominant species composition, differences between isolated and continuous birch forest were revealed even clearer. Only one species Pterostichus niger was generally abundant across all birch forests types, both isolated and continuous. Whereas, other recorded dominant species were abundant only in one of the forest types. The isolation influenced on the carabid diversity most clearly in birch forests with sphagnum cover, while in forests on the mineral soil islands within the peat bog the diversity parameters were similar to continuous adjacent forests. Distinct separation of carabid assemblages of continuous and isolated habitats was detected only in terms of species composition. Carabid assemblages of forests covered by sphagnum mosses were the most different compared to other.

Contrary to expectations, there is a clear increase of the abundances of forest species from continuous to isolated Betuletum myrtillosum forest type. Whereas in another isolated Betuletum ledo-sphagnosum type, as I expected, peat bog specialists were dominated. In isolated forests, a gradually decrease of the abundances of large-sized and brachypterous species and increase of medium-sized beetles were recorded. Variation in body size identified in present study corresponds to habitat islands theory, according to which in mainland or continuous habitats generally are characterized as having largebodied species, whereas isolated and smaller habitats are dominated by small-bodied species $[6,14,15]$. The abundance of macropterous species was the high only in isolated Betuletum myrtillosum forest type, and thus they are having a higher dispersal power. Other studies reported that the most specialized forest carabids, mostly wingless species tend to be more abundant as well in continuous forests than in smaller forest patches [16]. Flight loss is prevalent, as a rule, among dwellers of historically stable habitats [17]. In terms of carabid beetles, a stable habitat can be identified by a higher abundance of large-sized and brachypterous species [14, 16]. Hence, isolated birch forests within peatlands can be characterized as habitats with less stable environmental conditions in comparison with continuous forests.

Institutional Review Board Statement: The study was conducted according to the guidelines of the Declaration of Helsinki, and approved by the Ethics Committee of Vitebsk State University (no. 12 / 30.04.2021).

Informed Consent Statement: Not applicable.

Conflicts of Interest: The author declares that he haves no conflict of interest. 


\section{Appendix A}

Table A 1. Relative abundance (\%) and traits of carabid beetles species of of studied birch forest types.. Abbreviations used are: BF - continuous birch forests, BFI - isolated birch forests on the mineral soil, BFP - isolated birch forests on the peat soil; size classes 1 small $(0-5 \mathrm{~mm}), 2$ medium $(6-10 \mathrm{~mm}), 3$ large $(11-15 \mathrm{~mm})$ and 4 largest $(>15 \mathrm{~mm})$; habitat preferences - habitat generalists $(\mathrm{G})$, peat bog $(\mathrm{P})$, forest $(\mathrm{F})$ and open habitats $(\mathrm{O})$, wings: - brachypterous $(\mathrm{B})$, macropterous $(\mathrm{M})$, and dimorphic $(\mathrm{D})$.

\begin{tabular}{|c|c|c|c|c|c|c|}
\hline Species & $\mathrm{BF}$ & BFI & BFP & Size class & $\begin{array}{c}\text { Habitat } \\
\text { preferences }\end{array}$ & $\begin{array}{l}\text { Flight } \\
\text { ability }\end{array}$ \\
\hline Agonum ericeti (Panzer, 1809) & 0.00 & 0.00 & 34.60 & 2 & $\mathrm{P}$ & $\mathrm{D}$ \\
\hline A. marginatum (Linnaeus, 1758) & 0.21 & 0.00 & 0.00 & 3 & $\mathrm{O}$ & B \\
\hline Amara brunnea (Gyllenhal, 1810) & 0.95 & 12.33 & 0.47 & 2 & $\mathrm{~F}$ & M \\
\hline A. communis (Panzer, 1797) & 5.17 & 44.97 & 0.00 & 2 & $\mathrm{O}$ & M \\
\hline A. convexior Stephens, 1828 & 0.53 & 4.28 & 0.00 & 1 & $\mathrm{O}$ & M \\
\hline A. eurinota (Panzer, 1797) & 0.21 & 0.50 & 0.00 & 4 & $\mathrm{O}$ & M \\
\hline A.ovata (Fabricius, 1792) & 0.00 & 0.08 & 0.00 & 2 & G & M \\
\hline A. similata (Gyllenhal, 1810) & 0.11 & 0.50 & 0.00 & 2 & $\mathrm{O}$ & M \\
\hline Blethisa multipunctata (Linnaeus, 1758) & 0.00 & 0.34 & 0.00 & 4 & $\mathrm{O}$ & B \\
\hline Carabus cancellatus Illiger, 1798 & 12.13 & 0.00 & 0.00 & 4, & G & B \\
\hline C. granulatus Linnaeus, 1758 & 25.63 & 0.08 & 2.37 & 4 & G & $\mathrm{B}$ \\
\hline C. hortensis Linnaeus, 1758 & 5.27 & 0.25 & 0.00 & 4 & $\mathrm{~F}$ & B \\
\hline Calathus fuscipes (Goeze, 1777) & 0.00 & 0.17 & 0.00 & 4 & $\mathrm{O}$ & B \\
\hline C. melanocephalus (Linnaeus, 1758) & 0.00 & 1.51 & 0.00 & 3 & $\mathrm{~F}$ & $\mathrm{D}$ \\
\hline C. micropterus (Duftschmid, 1812) & 0.00 & 15.60 & 0.00 & 3 & $\mathrm{~F}$ & B \\
\hline Cychris caraboides (Duftschmid, 1812) & 2.22 & 0.34 & 2.84 & 4 & $\mathrm{~F}$ & B \\
\hline Epaphius secalis (Paykull, 1790) & 0.00 & 0.17 & 0.00 & 1 & $\mathrm{~F}$ & B \\
\hline Harpalus latus (Linnaeus, 1758) & 0.32 & 0.08 & 0.00 & 4 & $\mathrm{O}$ & M \\
\hline H. rufipes (Degeer, 1774) & 0.21 & 0.00 & 0.00 & 4 & $\mathrm{O}$ & M \\
\hline Leistus ferrugineus (Linnaeus, 1758) & 0.11 & 0.00 & 0.00 & 2 & $\mathrm{O}$ & $\mathrm{D}$ \\
\hline L. terminatus (Panzer,1793) & 0.21 & 0.42 & 0.00 & 2 & $\mathrm{~F}$ & $\mathrm{D}$ \\
\hline Loricera pilicornis (Fabricius, 1775) & 0.00 & 0.17 & 0.00 & 2 & G & M \\
\hline Nebria brevicollis (Fabricius, 1792) & 0.11 & 0.00 & 0.00 & 3 & $\mathrm{~F}$ & $\mathrm{D}$ \\
\hline Notiophilus palustris (Duftschmid, 1812) & 0.42 & 0.17 & 0.00 & 1 & $\mathrm{~F}$ & $\mathrm{D}$ \\
\hline Oxypselaphus obscurus (Herbst, 1784) & 0.11 & 0.17 & 0.00 & 2 & $\mathrm{~F}$ & $\mathrm{~B}$ \\
\hline Platynus assimilis (Paykull, 1790) & 0.11 & 0.25 & 0.00 & 4 & G & $\mathrm{D}$ \\
\hline P. krynickii (Sperk, 1835) & 0.63 & 0.00 & 0,00 & 2 & G & $\mathrm{D}$ \\
\hline Poecilus cupreus (Linnaeus, 1758) & 0.32 & 0.42 & 11.37 & 4 & $\mathrm{O}$ & M \\
\hline P.versicolor (Sturm, 1824) & 18.04 & 1.09 & 0.00 & 4 & $\mathrm{O}$ & $\mathrm{B}$ \\
\hline Pterostichus diligens (Sturm, 1824) & 0.00 & 0.00 & 20.38 & 2 & $\mathrm{P}$ & B \\
\hline P. melanarius (Illiger, 1798) & 1.69 & 0.67 & 0.47 & 4 & G & $\mathrm{D}$ \\
\hline P. minor (Gyllenhal, 1827) & 0.00 & 0.25 & 0.00 & 2 & $\mathrm{O}$ & $\mathrm{D}$ \\
\hline P. niger (Schaller, 1783) & 24.68 & 10.07 & 7.58 & 4 & G & B \\
\hline P. nigrita (Paykull, 1790) & 0.11 & 0.00 & 0.00 & 4 & G & M \\
\hline P. oblongopunctatus (Fabricius, 1787) & 0.11 & 4.36 & 0.00 & 4 & $\mathrm{~F}$ & $\mathrm{D}$ \\
\hline P. rhaeticus (Heer, 1838) & 0.00 & 0.76 & 19.91 & 2 & $\mathrm{P}$ & M \\
\hline P. strenuus (Panzer, 1797) & 0.11 & 0.00 & 0.00 & 2 & G & $\mathrm{D}$ \\
\hline P. vernalis (Panzer, 1797) & 0.21 & 0.00 & 0.00 & 2 & $\mathrm{O}$ & $\mathrm{D}$ \\
\hline Synuchus vivalis (Illiger, 1798) & 0.11 & 0.00 & 0.00 & 3 & G & $\mathrm{D}$ \\
\hline
\end{tabular}




\section{References}

1. Spitzer, K.; Danks, H.V. Insect biodiversity of boreal peat bogs. Annu. Rev. Entomol. 2006, 51, 137-161.

2. Zeliankevich, N.; Grummo, D.; Sozinov, O.; Galanina, O. Flora and Vegetation of the Raised Bogs of Belarus; Story Media Proekt: Minsk, Belaus; 2016; 244 p.

3. Rosenzweig, M.L. Species diversity in space and time; Cambridge University Press: New York, USA; 1995; 436 p.

4. Kingsolver, J.G.; Huey, R.B. Size, temperature, and fitness: three rules. Evol. Ecol. Res. 2008, 10(2), 251-268.

5. Jetz, W.; Carbone, C.; Fulford, J; Brown, J.H. The scaling of animal space use. Science, 2004, 306(5694), 266-268.

6. Lomolino, M.V. Body size evolution in insular vertebrates: generality of the island rule. J. Biogeogr. 2005, 32, 16831699.

7. Den Boer, P.J. Density limits and survival of local populations in 64 carabid species with different powers of dispersal. J. Evol. Biol. 1990, 3, 19-48.

8. Freude, H.; Harde, K.W.; Lohse, G.A.; Klausnitzer, B. Die Käfer Mitteleuropas, Band 2; Spectrum, Elsevier: München, Germany; 2004; 521 p.

9. Aleksandrowicz, O.R. Ground beetles (Coleoptera, Carabidae) of the West Part of Russian Plane. Fauna, zoogeography, ecology; Lambert Academic Publishing: Saarbrücken, Germany; 2014; 456 p. (In Russian; abstract in English).

10. Chao, A.; Colwell, R.K.; Lin, C.; Gotelli, N.J. Sufficient sampling for asymptotic minimum species richness estimators. Ecol. 2009, 90, 1125-1133.

11. R Development Core Team. R: a language and environment for statistical computing. R Foundation for Statistical Computing. Available online: https://www. R-project.org / (accessed on 14 March 2021).

12. Hammer, Ø.; Harper, D.A.T.; Ryan, P.D. PAST: paleontological statistics software package for education and data analysis. Palaeontol. Electron. 2001, 4, 1-9.

13. Desender, K. Theory versus reality: a review on the ecological and population genetic effects of forest fragmentation on wild organisms, with an emphasis on ground beetles. In: European Carabidology 2003. Procedings of the 11th European carabidologist meeting, Lövei, G.L., Toft, S., Eds.; DIAS: Aarhus, Denmark, 2005; DIAS report, no. 114, pp. 49-72.

14. Jelaska, L.Š.; Durbešić, P. Comparison of the body size and wing form of carabid species (coleoptera: Carabidae) between isolated and continuous forest habitats. Ann. Soc. Entomol. Fr. 2009, 45(3), 327-338.

15. Lövei, G.L.; Magura, T.; Tóthmérész, B.; Kodobocz, V. The influence of matrix habitat on ground beetle (Carabidae) species richness patterns in habitat islands, In: European Carabidology 2003. Procedings of the 11th European carabidologist meeting, Lövei, G.L., Toft, S., Eds.; DIAS: Aarhus, Denmark, 2005; DIAS report, no. 114, pp. 163-172.

16. Gaublomme, E.; Hendrickx, F.; Dhuyvetter, H.; Desender, K. The effects of forest patch size and matrix type on changes in carabid beetle assemblages in an urbanized landscape. Biol. Conserv. 2008, 141, 2585-2596.

17. Wagner, D.L.; Liebherr, J.K. Flightlessness in Insects. Tree. 1992, 7(7), 316-320. 